\title{
APORTE ATMOSFÉRICO DE AMÔNIO, NITRATO E SULFATO EM ÁREA DE FLORESTA OMBRÓFILA DENSA MONTANA NA SERRA DOS ÓRGÃOS, RJ
}

\author{
Renato de Aragão Ribeiro Rodrigues, William Zamboni de Mello* e Patricia Alexandre de Souza \\ Departamento de Geoquímica, Instituto de Química, Universidade Federal Fluminense, Outeiro de São João Batista, s/n,
} 24020-007 Niterói - RJ, Brasil

Recebido em 25/8/06; aceito em 18/5/07; publicado na web em 25/10/07

\begin{abstract}
ATMOSPHERIC DEPOSITION OF AMMONIUM, NITRATE AND SULFATE ON THE MONTANE DENSE OMBROPHILOUS FOREST IN SERRA DOS ÓRGÃOS, RJ. Wet and dry (dust) deposition was measured in the Serra dos Órgãos National Park. VWM $\mathrm{pH}$ was 5.3. Non-sea-salt (nss) $\mathrm{SO}_{4}^{2-}$ comprised $97 \%$ of total $\mathrm{SO}_{4}^{2-}$. The molar ratio $\left[2\left(\mathrm{nss}_{-} \mathrm{SO}_{4}^{2-}\right)+\mathrm{NO}_{3}^{-}\right] /\left[\mathrm{NH}_{4}^{+}+\mathrm{H}^{+}\right]$was 1.1 , suggesting that $\mathrm{pH}$ is predominantly controlled by $\mathrm{H}_{2} \mathrm{SO}_{4}, \mathrm{HNO}_{3}$, and $\mathrm{NH}_{3}$. Wet deposition of $\mathrm{NH}_{4}^{+}, \mathrm{NO}_{3}^{-}$, and nss- $\mathrm{SO}_{4}^{2-}$ was respectively $0.59,0.25$, and $0.30 \mathrm{kmol} \mathrm{ha}^{-1} \mathrm{yr}^{-1}$. Assuming that dry deposition of $\mathrm{N}$ can comprise $30-50 \%$ of its total (dry + wet) deposition, the latter is estimated to be $1.2-1.7 \mathrm{kmol} \mathrm{ha}^{-1} \mathrm{yr}^{-1}\left(17-24 \mathrm{~kg} \mathrm{~N} \mathrm{ha}^{-1} \mathrm{yr}^{-1}\right)$.
\end{abstract}

Keywords: rainwater chemistry; wet deposition; dry deposition.

\section{INTRODUÇÃO}

As deposições atmosféricas constituem uma das principais etapas da ciclagem e redistribuição dos vários elementos químicos sobre a superfície do planeta. Por isso, o seu conhecimento quantitativo é essencialmente importante para o entendimento dos ciclos biogeoquímicos e das influências antrópicas nos mesmos. As duas principais formas de deposição atmosférica são a úmida e a seca. A primeira compreende os processos de remoção de partículas e gases da atmosfera através da chuva, neblina ou neve. A segunda engloba todos os processos de transferência de partículas e gases para todos os tipos de superfície (plantas, solos, rochas, água e materiais) na ausência de chuva. Diferentemente da deposição úmida, estimar os fluxos de deposição seca é tarefa difícil face ao elevado número de variáveis envolvidas em seu controle ${ }^{1-3}$.

Desde meados do século XIX, atividades humanas voltadas à produção de energia e alimento vêm progressivamente aumentando não somente as emissões globais de carbono, mas também de nitrogênio $(\mathrm{N})$ e enxofre $(\mathrm{S})$ para a atmosfera. Dentre elas, a queima de combustíveis fósseis tem sido a principal responsável pelas emissões dos óxidos de nitrogênio $\left(\mathrm{NO}_{x}=\mathrm{NO}+\mathrm{NO}_{2}\right)$ e dióxido de enxofre $\left(\mathrm{SO}_{2}\right)$. Nos últimos 25 anos, as emissões globais antrópicas de amônia $\left(\mathrm{NH}_{3}\right)$ vêm crescendo progressivamente em função da produção e uso de fertilizantes sintéticos, queima de combustíveis fósseis, queima de biomassa e excreta humana e animal. Isso tem acarretado aumento da deposição atmosférica de amônio $\left(\mathrm{NH}_{4}^{+}\right)$, particularmente em algumas regiões do continente europeu e norte americano, onde as taxas de deposição de $\mathrm{N}$ são muito superiores àquelas atribuídas ao período pré-industrial ${ }^{4}$. Em suma, as perturbações causadas aos ciclos do $\mathrm{N}$ e $\mathrm{S}$ têm comprometido a qualidade do ar (com efeitos adversos à saúde humana), provocando o declínio de florestas ("forest dieback"), a acidificação de ecossistemas 5 e a eutroficação de lagos e estuários ${ }^{6,7}$.

Dentre as várias florestas tropicais da Terra, a Floresta Atlântica é apontada pela comunidade científica internacional como uma das mais ameaçadas de desaparecimento e o estado do Rio de Janeiro é um dos seus maiores centros de endemismos ${ }^{8}$. Recentemen-

*e-mail: zamboni@geoq.uff.br te, Phoenix et al. ${ }^{9}$ alertaram para potenciais impactos negativos que poderão resultar do elevado aporte atmosférico de $\mathrm{N}$ em alguns setores da Floresta Atlântica (especialmente na Região Sudeste do Brasil) por ser uma das áreas de maior diversidade florística e endemismo do planeta. Segundo Phoenix et al. ${ }^{9}$, em meados da década de 90 quase $32 \%$ de toda a área com cobertura de Floresta Atlântica recebeu um aporte atmosférico de $\mathrm{N}$ na faixa de $10-15 \mathrm{~kg}$ $\mathrm{N} \mathrm{ha}^{-1} \mathrm{ano}^{-1}$ e é previsto que em meados do século XXI cerca de $95 \%$ e $68 \%$ da Floresta Atlântica devam receber aportes atmosféricos respectivamente superiores a 10 e $15 \mathrm{~kg} \mathrm{~N} \mathrm{ha}^{-1} \mathrm{ano}^{-1}$.

Recente inventário de emissões de poluentes atmosféricos da região metropolitana do Rio de Janeiro (RMRJ), elaborado pela Fundação Estadual de Engenharia do Meio Ambiente (FEEMA) ${ }^{10}$, apresenta taxas de emissão de $\mathrm{SO}_{2}$ e $\mathrm{NO}_{\mathrm{x}}$ de $32 \mathrm{Gg} \mathrm{S}$ ano ${ }^{-1}$ (1 Gmol ano $\left.^{-1}\right)$ e $29 \mathrm{Gg} \mathrm{N}$ ano $^{-1}\left(2 \mathrm{Gmol} \mathrm{ano}^{-1}\right)$ [G (giga) $=10^{9}$ ]. De acordo com o inventário da FEEMA $^{10}$, as fontes fixas contribuíram com $88 \%$ do total das emissões de $\mathrm{SO}_{2}$ e as fontes móveis com $67 \%$ do total das emissões de $\mathrm{NO}_{\mathrm{x}}$. As indústrias petroquímicas foram responsáveis por $45 \%$ do total das emissões de $\mathrm{SO}_{2}$ e $13 \%$ do total das emissões de $\mathrm{NO}_{x}$. Sabe-se que toda essa quantidade de poluentes lançada à atmosfera deve retornar à superfície. Entretanto, até então não se conhece a abrangência da dispersão desses poluentes e quais são as áreas predominantemente receptoras. A direção predominante dos ventos de superfície na entrada da Baía de Guanabara e suas proximidades é a do quadrante sul ${ }^{11,12}$. Sendo assim, é possível que uma parte dos poluentes atmosféricos procedentes dessas emissões sejam transportados e depositados no trecho da Serra do Mar situado ao norte da Bacia da Baía de Guanabara e especialmente sobre as vertentes voltadas para o Atlântico.

O presente trabalho teve como objetivo estimar o aporte atmosférico de amônio $\left(\mathrm{NH}_{4}^{+}\right)$, nitrato $\left(\mathrm{NO}_{3}^{-}\right)$e sulfato $\left(\mathrm{SO}_{4}^{2-}\right)$ no trecho de Floresta Ombrófila Densa Montana da Serra dos Órgãos (FODM) $(\mathrm{RJ})$, área potencialmente susceptível às influências das deposições de poluentes atmosféricos oriundos das emissões antrópicas da RMRJ. A susceptibilidade potencial dessa área deve-se não somente à quantidade de poluentes emitidos pela RMRJ, mas a algumas outras variáveis, tais como relevo e distância das fontes emissoras, e elementos climáticos, como ventos predominantes e pluviosidade. 


\section{PARTE EXPERIMENTAL}

\section{Área de estudo}

O presente estudo foi realizado no trecho da Serra dos Órgãos com cobertura de Floresta Ombrófila Densa Montana (Floresta Tropical Pluvial). A Serra dos Órgãos, cujo ponto culminante é a Pedra do Sino (2263 m), é o nome local da Serra do Mar cujas vertentes íngremes voltadas para o Atlântico formam o limite norte da bacia hidrográfica da Baía de Guanabara. A Serra dos Órgãos possui coberturas de vegetação que variam, de acordo com a altitude, de Floresta Ombrófila Densa Submontana até Campo de Altitude.

O ponto de coleta das amostras de deposição úmida e seca situa-se nas proximidades da Sede do Parque Nacional da Serra dos Órgãos (PARNASO), em Teresópolis, $\mathrm{RJ}^{13}$. Sua sede localiza-se a

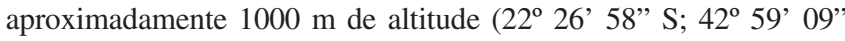
W), na bacia do alto curso do rio Paquequer, e está a cerca de 55 e $60 \mathrm{~km}$ a norte-nordeste dos centros das cidades de Niterói e Rio de Janeiro, respectivamente. A bacia do alto curso do rio Paquequer é adjacente às bacias dos altos cursos dos rios Iconha e Soberbo que drenam suas águas em direção à Baía de Guanabara. O trecho do rio Soberbo localizado no PARNASO preserva a maior fração de mata primária da região. O PARNASO possui flora e fauna ricas, com grande número de espécies endêmicas e ameaçadas de extinção ${ }^{14}$

O clima no PARNASO varia em função da altitude. As partes mais elevadas do parque, tais como as do Parque Nacional do Itatiaia, registram as temperaturas mais baixas do RJ. Na Sede do PARNASO $(\sim 1000 \mathrm{~m})$, as médias mensais históricas indicam temperatura na faixa de $14,3{ }^{\circ} \mathrm{C}$ (julho) a $19,2{ }^{\circ} \mathrm{C}$ (fevereiro) e precipitação de $88 \mathrm{~mm}$ (junho) a $408 \mathrm{~mm}$ (dezembro) ${ }^{11}$. Nesta altitude as médias anuais de temperatura e precipitação são $17,6{ }^{\circ} \mathrm{C}$ e 2813 $\mathrm{mm}^{11}$. Nas altitudes mais elevadas, a temperatura atinge valores inferiores a $0{ }^{\circ} \mathrm{C}$ nos dias de inverno e a precipitação anual pode atingir até $3600 \mathrm{~mm}$. Devido à proximidade ao oceano $(\sim 50 \mathrm{~km})$, a serra torna-se uma barreira para a entrada das massas de ar úmidas vindas do Atlântico. Em virtude disso, as chuvas orográficas sobre as vertentes voltadas para o Atlântico fazem com que estas sejam mais úmidas que aquelas voltadas para o continente (i.e., as que compreendem o vale do rio Paraíba do Sul).

\section{Coleta de amostras}

No período de 30/11/2004 a 22/11/2005 foram coletadas amostras de deposição úmida $(\mathrm{n}=40)$ e seca $(\mathrm{n}=45)$ por intermédio de um coletor automático Graseby/GMW modelo APS ("Acid Precipitation Sampler") 78-100 ${ }^{15}$ (Figura 1). O equipamento, com estrutura robusta de alumínio (largura $=51 \mathrm{~cm}$; comprimento $=$ $102 \mathrm{~cm}$; altura $=124 \mathrm{~cm}$; peso $\sim 40 \mathrm{~kg}$ ), possui dois compartimentos de coleta dispostos simetricamente, cada um deles contendo um balde de plástico de formato cilíndrico (altura $=28 \mathrm{~cm}$; d.i. $=$ $29 \mathrm{~cm}$ ), destinados à coleta da deposição úmida (água de chuva exclusivamente) e da deposição seca (predominantemente partículas depositadas por ação gravitacional). $\mathrm{O}$ equipamento conta com um sensor elétrico que controla alternadamente, através de uma tampa móvel (teto de duas águas), a abertura e fechamento (e vedação) desses recipientes. Com o início da precipitação, o sensor aciona um motor que desloca a tampa do balde coletor da deposição úmida e para o balde coletor de deposição seca. Ao término da precipitação, por movimento reverso, a tampa fecha o balde coletor da deposição úmida, evitando tanto a influência da deposição seca sobre a água da chuva coletada quanto a sua evaporação.

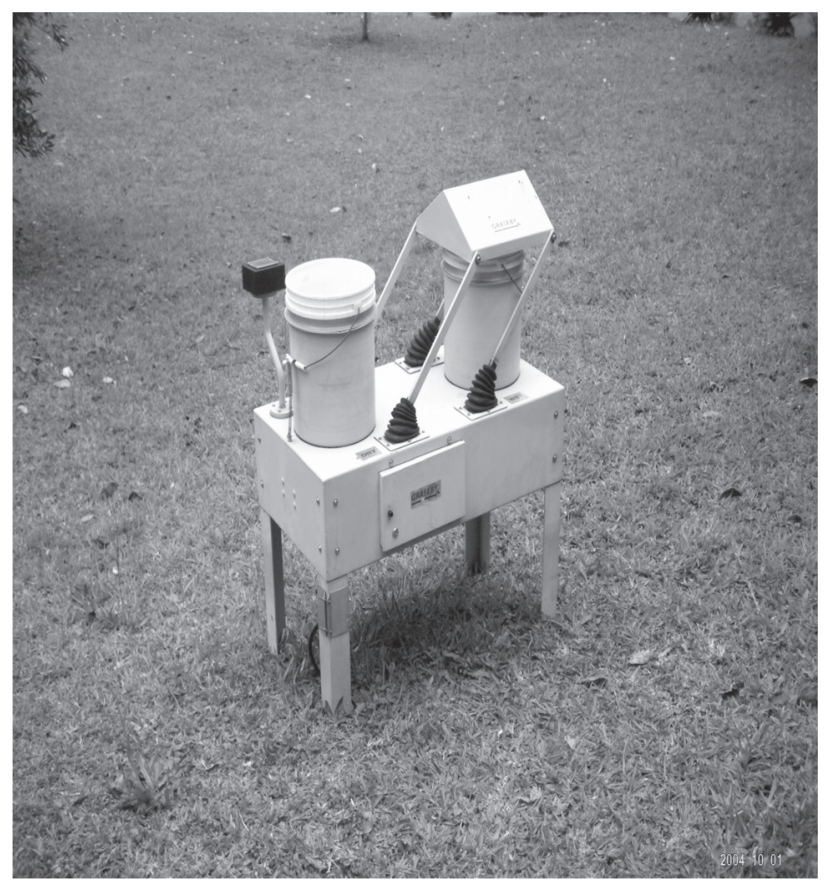

Figura 1. Coletor automático de deposição úmida e seca instalado na sede do Parque Nacional da Serra dos Órgãos (Teresópolis, RJ)

O uso desse equipamento é bem adequado para estimativa dos fluxos de deposição úmida de espécies químicas iônicas, entretanto é inadequado para estimativa dos fluxos de deposição (seca) de gases muito solúveis em água e que podem reagir com diferentes tipos de superfícies de deposição, tais como $\mathrm{SO}_{2}, \mathrm{NH}_{3}, \mathrm{NO}_{2}$ (dióxido de nitrogênio), $\mathrm{HNO}_{3}$ (ácido nítrico) e $\mathrm{N}_{2} \mathrm{O}_{5}$ (pentóxido de dinitrogênio). Os fluxos de deposição seca desses gases podem representar uma parcela significativa da deposição total de $\mathrm{N}$ e $\mathrm{S}^{2,3,16-18}$. Em se tratando de deposição seca, a técnica utilizada neste trabalho é mais eficiente para coleta e estimativa da deposição de partículas sedimentáveis ("settling particles"), i.e., aquelas de tamanho superior a $2,5 \mu \mathrm{m}^{17}$.

As amostras de água de chuva e deposição seca foram recolhidas de 7 em 7 dias. A cada coleta, uma alíquota da água de chuva, resultante de um ou mais eventos ocorridos neste período, foi transferida para um frasco de polietileno (Nalgon) de $500 \mathrm{~mL}$. Durante o período de estiagem, houve semanas sem ocorrência de chuvas. O volume total de chuva acumulada foi anotado para posterior cálculo da precipitação acumulada no período. O procedimento adotado para recolhimento da amostra de deposição seca encontra-se descrito detalhadamente em de Souza et al. ${ }^{15}$. Após recolhidas, as amostras de água de chuva e de deposição seca (dissolvidas em água) foram imediatamente transportadas para o Laboratório de Biogeoquímica de Ambientes Tropicais, do Departamento de Geoquímica da Universidade Federal Fluminense.

Vale ressaltar que não houve adição de biocida para conservação das amostras enquanto estocadas nos baldes coletores. Galloway e Likens ${ }^{19}$ sugeriram que para determinação de íons inorgânicos em água de chuva as amostras devem ser coletadas por evento ou no máximo semanalmente, alegando que períodos superiores podem acarretar alteração da sua composição química. Em amostras de água de chuva (não filtradas) mantidas a temperatura ambiente com e sem a adição de timol [5-metil-2-(1-metiletil) fenol] como biocida, Ayers et al. ${ }^{20}$ observaram que, após várias semanas, as concentrações de $\mathrm{NO}_{3}^{-}$e $\mathrm{SO}_{4}^{2-}$ nas amostras sem timol não se alteraram ao passo que as de $\mathrm{NH}_{4}^{+}$apresentaram perdas que variaram 
de 2 a $20 \%$ (em média 11\%). Portanto, considerando-se que as coletas foram efetuadas semanalmente, a possibilidade de perda, por atividade microbiológica, de uma parcela do $\mathrm{NH}_{4}^{+}$presente na amostra, não deve ser descartada.

\section{Tratamento de amostras e análises químicas}

No laboratório, alíquotas das amostras de água de chuva e deposição seca foram imediatamente filtradas através de membranas de acetato de celulose com diâmetro de poro de 0,22 $\mu \mathrm{m}$. Em alíquotas não filtradas, foram prontamente efetuadas as medidas de $\mathrm{pH}$ e condutividade com equipamentos WTW modelos pH330 e LF330, respectivamente. Também em alíquotas não filtradas foi determinado o íon $\mathrm{NH}_{4}^{+}$pelo método de azul de indofenol, com absorbância medida num espectrofotômetro Hitachi, modelo U-1100. A não filtragem das amostras para a determinação do íon $\mathrm{NH}_{4}^{+}$tem como propósito evitar ou minimizar a possibilidade de contaminação das mesmas por dissolução de $\mathrm{NH}_{3}$ do ar. A absorbância medida em amostras não filtradas de água de chuva e deposição seca mostrou valores muito inferiores $(<0,006)$ aos do branco dos padrões, que, em geral, é de $0,025 \pm 0,005$. Os ânions $\mathrm{NO}_{3}^{-}$e $\mathrm{SO}_{4}{ }^{2-}$ foram analisados por cromatografia líquida (Shimadzu, modelo LC-10AD), equipada com detector de condutividade (CDD-6A) ${ }^{15}$. O íon $\mathrm{Na}^{+}$foi analisado por espectrofotometria de emissão de chama (Baird Atomic, modelo 4200; Varian, modelo SpectraAA-300). As análises de $\mathrm{NH}_{4}^{+}$ foram, em geral, efetuadas em até uma semana após a chegada das amostras ao laboratório, enquanto que as de $\mathrm{NO}_{3}^{-}$e $\mathrm{SO}_{4}{ }^{2-}$ foram efetuadas em até um mês. Quando as análises dos íons não ocorriam no mesmo dia da chegada das amostras ao laboratório, as alíquotas (filtradas e não filtradas) eram armazenadas em freezer $\left(\mathrm{T}=-22^{\circ} \mathrm{C}\right)$. Os limites de detecção dos íons analisados foram (em $\left.\mu \mathrm{mol} \mathrm{L} \mathrm{L}^{-1}\right)$ : $\mathrm{Na}^{+}$ $(1,0), \mathrm{NH}_{4}^{+}(0,2), \mathrm{NO}_{3}^{-}(0,2)$ e $\mathrm{SO}_{4}^{2-}(0,2)$. A precisão das análises químicas, calculada através do coeficiente de variação, encontra-se na faixa de $\pm 5 \%$ (para $n=3$ ).

\section{RESULTADOS E DISCUSSÃO}

\section{Composição química da água da chuva}

A Tabela 1 apresenta a estatística descritiva referente às medidas de $\mathrm{pH}$ e concentrações de sódio $\left(\mathrm{Na}^{+}\right)$, amônio $\left(\mathrm{NH}_{4}^{+}\right)$, nitrato $\left(\mathrm{NO}_{3}^{-}\right)$e sulfato $\left(\mathrm{SO}_{4}^{2-}\right)$ efetuadas num total de 40 amostras de água de chuva, coletadas no trecho com cobertura de FODM no PARNASO. Em amostras de água de chuva coletadas no trecho da sede do Parque Nacional do Itatiaia (PNI) $(820 \mathrm{~m}$ de altitude; $~ 100 \mathrm{~km}$ do Oceano Atlântico), de Mello e Almeida ${ }^{21}$ atribuíram ao aerossol de sal marinho ("sea-salt aerosol") a origem principal daqueles íons. Assumindo-se que na área de estudo do PARNASO ( $1000 \mathrm{~m}$ de altitude; $60 \mathrm{~km}$ do Oceano Atlântico) o íon $\mathrm{Na}^{+}$tem sua origem exclusivamente marinha, este foi utilizado para o cálculo da parcela de $\mathrm{SO}_{4}^{2-}$ proveniente do aerossol de sal marinho e estimativa do excesso de $\mathrm{SO}_{4}^{2-}$ (doravante abreviado por exc- $\left.\mathrm{SO}_{4}^{2-}\right)^{15,22}$, i.e., a parcela do $\mathrm{SO}_{4}^{2-}$ total cuja origem é a oxidação do $\mathrm{SO}_{2}$ (de fontes naturais e antrópicas). Dessa forma, estimou-se que, na água da chuva do PARNASO, o exc- $\mathrm{SO}_{4}{ }^{2-}$ corresponda a $97 \%$ do $\mathrm{SO}_{4}{ }^{2-}$ total. Na região, as possíveis fontes de $\mathrm{SO}_{2}$ são principalmente a queima de combustíveis fósseis, a oxidação do sulfeto de dimetila $\left(\mathrm{CH}_{3} \mathrm{SCH}_{3}\right)$ emitido pelas águas oceânicas e a oxidação do sulfeto de hidrogênio $\left(\mathrm{H}_{2} \mathrm{~S}\right)$ emitido pelos sedimentos marginais da Baía de Guanabara. Acredita-se, entretanto, que a primeira tenha sua contribuição predominante em relação às demais.

Os valores de condutividade elétrica variaram de 0,8 a 28,6 $\mu \mathrm{S}$ $\mathrm{cm}^{-1}$, com média ponderada pelo volume (MPV) de $6,8 \mu \mathrm{S} \mathrm{cm}^{-1}$
Tabela 1. Composição química parcial da água da chuva (concentrações em $\mu$ mol $\mathrm{L}^{-1} ; \mathrm{n}=40$ ) na sede do Parque Nacional da Serra dos Órgãos (Teresópolis, RJ) no período de 30 de novembro de 2004 a 22 de novembro de 2005

\begin{tabular}{lcrccc}
\hline & MPV & MA & Mediana & Mínimo & Máximo \\
\hline $\mathrm{pH}$ & 5,26 & 5,26 & 5,56 & 4,50 & 6,85 \\
$\mathrm{H}^{+}$ & 5,4 & 5,5 & 2,8 & 0,1 & 31,6 \\
$\mathrm{Na}^{+}$ & 6,0 & 9,0 & 4,5 & 2,3 & 49,7 \\
$\mathrm{NH}_{4}^{+}$ & 20,9 & 22,3 & 15,4 & 1,1 & 44,2 \\
$\mathrm{NO}_{3}^{-}$ & 8,7 & 8,7 & 7,1 & 0,9 & 34,4 \\
$\mathrm{SO}_{4}^{2-}$ & 11,0 & 10,3 & 8,5 & 1,2 & 15,3 \\
Exc- $^{-}$ & 10,7 & 9,7 & 8,2 & & \\
\hline
\end{tabular}

MPV - média ponderada pelo volume; MA - média aritmética.

(média aritmética $=7,2 \mu \mathrm{S} \mathrm{cm} \mathrm{cm}^{-1}$; mediana $=5,6 \mu \mathrm{S} \mathrm{cm}^{-1}$ ). O total de chuva precipitada durante o período de estudo foi de $2830 \mathrm{~mm}$, valor muito próximo à média anual de longo prazo $(2813 \mathrm{~mm})$ medida na Estação Parque Nacional da Serra dos Órgãos (22 $27^{\circ}$ ' $\mathrm{S} ; 42^{\circ} 56^{\prime} \mathrm{W}$; altitude $\left.=959 \mathrm{~m}\right)$, hoje desativada ${ }^{11}$.

Os valores de $\mathrm{pH}$ variaram de 4,50 a 6,85. O pH calculado a partir da concentração MPV de $\mathrm{H}^{+}$(doravante referido como $\mathrm{pH}$ médio) foi 5,26 , que corresponde a uma acidez livre de $5,4 \mu \mathrm{mol} \mathrm{L} \mathrm{L}^{-1}$. O pH médio da chuva na FODM do PARNASO foi inferior àquele resultante da dissolução do dióxido de carbono $\left(\mathrm{CO}_{2}\right)$ da atmosfera (370 ppm) em água pura $(\mathrm{pH}=5,63)$ e superior ao valor proposto por Galloway et $a l .{ }^{23}(\mathrm{pH}=5,0)$ como o limite inferior de $\mathrm{pH}$ para águas de chuva cuja acidez é originada de substâncias provenientes de processos naturais. Do total dos valores de $\mathrm{pH}$ medidos, $13 \%$ foram inferiores a 5,0 e 55\% deles à 5,6, e, além disso, 30\% são superiores a 6,0.

No PARNASO, o pH médio da chuva foi maior que o verificado nas proximidades da sede do Parque Nacional do Itatiaia (PNI) ( $\mathrm{pH}=4,94)$, localizado a cerca de $820 \mathrm{~m}$ de altitude no maciço do Itatiaia (RJ) ${ }^{21}$ (Tabela 2). Tanto no PARNASO quanto no PNI a razão molar média $\left[2\left(\right.\right.$ exc- $\left.\left.\mathrm{SO}_{4}^{2-}\right)+\mathrm{NO}_{3}^{-}\right] /\left[\mathrm{NH}_{4}^{+}+\mathrm{H}^{+}\right]$foi 1,1 , indicando que nestes locais o ácido sulfúrico $\left(\mathrm{H}_{2} \mathrm{SO}_{4}\right)$, o ácido nítrico $\left(\mathrm{HNO}_{3}\right)$ e a amônia $\left(\mathrm{NH}_{3}\right)$ são os principais ácidos e base responsáveis pelo controle do $\mathrm{pH}$ da água da chuva. Proporcionalmente, as concentrações de $\mathrm{NH}_{4}^{+}$em relação às de $\mathrm{H}^{+}$foram maiores no PARNASO do que no PNI, o que deve explicar o maior valor do $\mathrm{pH}$ médio do primeiro em relação ao segundo (Tabela 2).

A Tabela 3 mostra valores de $\mathrm{pH}$ e concentrações de $\mathrm{H}^{+}$livre (calculadas a partir dos valores de $\mathrm{pH}$ ), como também valores de $\mathrm{Na}^{+}, \mathrm{NH}_{4}^{+}, \mathrm{NO}_{3}^{-}$e $\mathrm{SO}_{4}^{2-}$ (total e excesso) medidos em amostras de águas de chuva coletadas em áreas remotas do planeta, onde a in-

Tabela 2. Comparação entre a composição química (concentrações MPV* em $\mu \mathrm{mol} \mathrm{L} \mathrm{L}^{-1}$ ) parcial da água da chuva na sede do Parque Nacional da Serra dos Órgãos (PARNASO; Teresópolis, RJ; altitude $=1000 \mathrm{~m}$ ) e sede do Parque Nacional do Itatiaia (PNI; Itatiaia, $\mathrm{RJ}$; altitude $=820 \mathrm{~m}$ )

\begin{tabular}{lcc}
\hline & PARNASO & PNI $^{\mathrm{a}}$ \\
\hline $\mathrm{pH}$ & 5,26 & 4,94 \\
$\mathrm{H}^{+}$ & 5,4 & 11,6 \\
$\mathrm{Na}^{+}$ & 6,0 & 3,9 \\
$\mathrm{NH}_{4}^{+}$ & 20,9 & 13,5 \\
$\mathrm{NO}_{3}^{-}$ & 8,7 & 11,8 \\
$\mathrm{SO}_{4}^{2-}$ & 11,0 & 7,8 \\
$\mathrm{Exc}^{2-} \mathrm{SO}_{4}^{2-}$ & 10,7 & 7,6 \\
\hline
\end{tabular}

* MPV - média ponderada pelo volume; ${ }^{\text {a }}$ ref. 21 
Tabela 3. Composição química (concentrações MPV* em $\mu$ mol L ${ }^{-1}$ ) parcial de águas de chuva de regiões remotas continentais (América do Sul) e oceânicas

\begin{tabular}{lcccc}
\hline & $\begin{array}{c}\text { San Carlos } \\
\text { (Venezuela) }\end{array}$ & $\begin{array}{c}\text { Lago Calado }^{\mathrm{a}} \\
\text { (AM, Brasil) }\end{array}$ & $\begin{array}{c}\text { Torres del Paine }^{\mathrm{c}} \\
\text { (Chile) }\end{array}$ & $\begin{array}{c}\text { Ilha Amsterdam }^{\mathrm{d}} \\
(\text { Oceano Índico) }\end{array}$ \\
\hline $\mathrm{pH}$ & 4,81 & 4,77 & 4,96 & 5,06 \\
$\mathrm{H}^{+}$ & 15,5 & 17,0 & 10,9 & 8,8 \\
$\mathrm{Na}^{+}$ & 1,8 & 2,4 & 13,2 & 206,5 \\
$\mathrm{NH}_{4}^{+}$ & 2,3 & 3,0 & 0,6 & 1,8 \\
$\mathrm{NO}_{3}^{-}$ & 2,6 & 4,2 & 0,5 & 1,3 \\
$\mathrm{SO}_{4}^{2-}$ & 1,5 & 1,0 & 1,4 & 14,6 \\
Exc-SO $_{4}^{2-}$ & 1,4 & $0,9 * *$ & 0,6 & 2,5 \\
Precipitação $\left(\mathrm{mm} \mathrm{ano}^{-1}\right)$ & 3914 & 2754 & 750 & 1120 \\
\hline
\end{tabular}

* MPV - média ponderada pelo volume; ** Valor não fornecido pelos autores, porém calculado com base nas concentrações de $\mathrm{Na}^{+}$e $\mathrm{SO}_{4}^{2-}$;

${ }^{\mathrm{a}}$ ref. $23 ;{ }^{\mathrm{b}}$ ref. $24 ;{ }^{\mathrm{c}}$ ref. $30 ;{ }^{\mathrm{d}}$ ref. 25.

fluência antrópica pode ter sido mínima no período em que foram realizadas. Dentre estes locais, as concentrações MPV mais altas de $\mathrm{NH}_{4}^{+}\left(3,0 \mu \mathrm{mol} \mathrm{L}{ }^{-1}\right)$ e $\mathrm{NO}_{3}^{-}\left(4,2 \mu \mathrm{mol} \mathrm{L}{ }^{-1}\right)$ foram verificadas nas águas de chuva coletadas no Lago Calado (Bacia Amazônica), onde, segundo os autores ${ }^{24}$, a composição química das águas de chuva não foi significativamente influenciada pelas queimadas, embora tenham verificado uma concentração MPV de $\mathrm{NH}_{4}^{+}$seis vezes maior no período seco em relação ao chuvoso. As concentrações MPV de exc- $\mathrm{SO}_{4}^{2-}$ em regiões remotas continentais $\left(<1,5 \mu \mathrm{mol} \mathrm{L}^{-1}\right)^{23,24}$ são inferiores às da Ilha Amsterdam $\left(2,5 \mu \mathrm{mol} \mathrm{L}{ }^{-1}\right)^{25}$. A maior concentração de exc- $\mathrm{SO}_{4}^{2-}$ na água da chuva da Ilha Amsterdam em relação às regiões continentais (Tabela 3) é explicada em virtude da maior emissão de gases reduzidos de enxofre (e.g., $\mathrm{CH}_{3} \mathrm{SCH}_{3}$ e $\mathrm{H}_{2} \mathrm{~S}$ ) dos ecossistemas marinhos comparados com os dos ecossistemas tropicais continentais ${ }^{26-28}$.

Em suma, as concentrações individuais de $\mathrm{NH}_{4}^{+}, \mathrm{NO}_{3}^{-}$e exc$\mathrm{SO}_{4}^{2-}$ no período pré-industrial devem ter sido da ordem de $2 \pm 1$ $\mu \mathrm{mol} \mathrm{L} \mathrm{L}^{-1}$. Portanto, adotando-se esse valor como referência de água de chuva desprovida de constituintes químicos oriundos de atividades antrópicas, constata-se que no PARNASO o íon $\mathrm{NH}_{4}^{+}$(Tabela 1) é aquele que apresenta a maior discrepância (uma ordem de grandeza) em relação ao que deveria ter sido sua concentração média no período pré-industrial. As concentrações médias de $\mathrm{NO}_{3}^{-}$e exc$\mathrm{SO}_{4}^{2-}$ no PARNASO são respectivamente quatro e cinco vezes superiores ao que deveriam ter sido suas concentrações em água de chuva no período pré-industrial.

\section{Fluxos de deposição úmida}

No PARNASO, os fluxos de deposição úmida do período estu- dado representam o somatório dos fluxos de deposição semanal, calculados a partir do produto das concentrações dos íons pelas respectivas alturas de chuva acumuladas semanalmente. Entretanto, os mesmos resultados podem ser obtidos a partir da multiplicação das concentrações MPV compiladas na Tabela 1 pelo total de chuva precipitada no período de estudo, ou seja, $2830 \mathrm{~mm} \mathrm{ano}^{-1}$.

A Tabela 4 apresenta os fluxos de deposição úmida dos íons $\mathrm{H}^{+}, \mathrm{NH}_{4}^{+}, \mathrm{NO}_{3}^{-}, \mathrm{SO}_{4}^{2-}$ e exc- $\mathrm{SO}_{4}^{2-}$ no PARNASO e em algumas áreas remotas do mundo. Através da análise comparativa desses resultados, percebe-se o quanto mais altos são os fluxos de $\mathrm{N}$ inorgânico $\left(\mathrm{NH}_{4}^{+}+\mathrm{NO}_{3}^{-}\right)$e $\mathrm{SO}_{4}^{2-}$ na FODM do PARNASO em relação às áreas remotas mencionadas. Por outro lado, os fluxos de $\mathrm{H}^{+}$são inferiores àqueles medidos na Bacia Amazônica, onde os ácidos carboxílicos, especialmente o fórmico e o acético, exercem papel importante no controle desse íon ${ }^{28,29}$. Os fluxos de $\mathrm{H}^{+}$do PARNASO são ligeiramente maiores que aqueles medidos em áreas oceânica (Ilha Amsterdam) ${ }^{25}$ e montanhosa (Torres del Paine, Chile) ${ }^{30}$.

Na FODM do PARNASO, o fluxo de deposição úmida de $\mathrm{N}$ inorgânico foi de $838 \mathrm{~mol} \mathrm{ha}^{-1} \mathrm{ano}^{-1}$, dos quais $70 \%$ foram devidos ao $\mathrm{NH}_{4}^{+}$e o restante ao $\mathrm{NO}_{3}^{-}$. Nas duas áreas remotas situadas na Bacia Amazônica, Lago Calado (AM) ${ }^{24}$ e San Carlos de Rio Negro (Venezuela) ${ }^{22}$, os fluxos de deposição úmida de $\mathrm{N}$ inorgânico foram bastante semelhantes entre si e próximos aos $200 \mathrm{~mol} \mathrm{ha}^{-1} \mathrm{ano}^{-1}$, dos quais $45-50 \%$ foram devidos ao $\mathrm{NH}_{4}^{+}$. Em El Verde (Floresta Experimental de Luquillo, Porto Rico), a cerca de $400 \mathrm{~m}$ acima do nível do mar e $10 \mathrm{~km}$ de distância do mar, onde a precipitação anual é da ordem de $3500 \mathrm{~mm}$, McDowell et al. ${ }^{31}$ mediram um fluxo de deposição úmida de $\mathrm{N}$ inorgânico de $251 \mathrm{~mol} \mathrm{ha}^{-1} \mathrm{ano}^{-1}$, dos quais cerca de $40 \%$ foram atribuídos ao $\mathrm{NH}_{4}{ }^{+}$. Segundo McDowell et al. ${ }^{31}$, parte do aporte de $\mathrm{NO}_{3}{ }^{-}$em El Verde é de origem

Tabela 4. Fluxos de deposição úmida (em mol ha-1 ano $\left.^{-1}\right)^{*}$ no Parque Nacional da Serra dos Órgãos e de regiões remotas continentais (América do Sul) e oceânicas

\begin{tabular}{|c|c|c|c|c|c|}
\hline & $\begin{array}{c}\text { PARNASO } \\
\text { (Teresópolis, RJ) }\end{array}$ & $\begin{array}{l}\text { San Carlos } \\
\text { (Venezuela) }\end{array}$ & $\begin{array}{l}\text { Lago Calado }^{\mathrm{b}} \\
\text { (AM, Brasil) }\end{array}$ & $\begin{array}{l}\text { Torres del Paine } \\
\text { (Chile) }\end{array}$ & $\begin{array}{l}\text { Ilha Amsterdam } \\
\text { (Oceano Índico) }\end{array}$ \\
\hline $\mathrm{H}^{+}$ & 154 & 607 & 468 & 82 & 99 \\
\hline $\mathrm{NH}_{4}^{+}$ & 591 & 90 & 82 & 5 & 20 \\
\hline $\mathrm{NO}_{3}^{-}$ & 247 & 102 & 115 & 4 & 15 \\
\hline $\mathrm{SO}_{4}^{2-}$ & 311 & 57 & 54 & 11 & 164 \\
\hline Exc- $\mathrm{SO}_{4}^{2-}$ & 302 & 53 & $50 * *$ & 5 & 27 \\
\hline Precipitação & 2830 & 3914 & 2754 & 750 & 1120 \\
\hline
\end{tabular}

$* 1$ ha $=10^{4} \mathrm{~m}^{2} ; * *$ Valor não fornecido pelos autores, porém calculado com base nas concentrações de $\mathrm{Na}^{+}$e $\mathrm{SO}_{4}^{2-;}{ }^{2}$ ref. $23 ;{ }^{b}$ ref. 24 ; ${ }^{\mathrm{c}}$ ref. $30 ;{ }^{\mathrm{d}}$ ref. 25 . 
antrópica, transportado da América do Norte em direção ao Caribe pelas frentes frias, especialmente no inverno. Enquanto o fluxo de deposição de $\mathrm{NO}_{3}{ }^{-}$no PARNASO esteve na faixa dos fluxos mais elevados registrados nos EUA em 2004 pelo NADP/NTN ("National Atmospheric Deposition Program/National Trends Network"), o de $\mathrm{NH}_{4}^{+}$superou em quase duas vezes os valores mais altos dos EUA naquele mesmo ano, verificados no nordeste do estado do Iowa e sudeste do estado da Pennsylvania ${ }^{32}$.

O fluxo de deposição úmida de $\mathrm{N}$ inorgânico na FODM do PARNASO é maior que aquele medido por de Mello e Almeida ${ }^{21}$ (383 $\mathrm{mol} \mathrm{ha}^{-1}$ ano $^{-1}$ ), em ecossistema semelhante, nas proximidades da sede do Parque Nacional do Itatiaia (PNI), onde a contribuição de $\mathrm{NH}_{4}^{+}$foi de 53\%. Fluxo maior foi estimado por Vautz et al. ${ }^{33}$ para o trecho da Floresta Atlântica (Serra do Mar) situado nas proximidades do complexo industrial de Cubatão (SP), que foi de $1420 \mathrm{~mol}$ ha $^{-1}$ ano $^{-1} \mathrm{e}$ dos quais $66 \%$ foram atribuídos ao $\mathrm{NH}_{4}^{+}$. Em Cubatão, as emissões de $\mathrm{NH}_{3}$ em 1997 foram da ordem de $93 t \mathrm{~N}^{2}$ ano $^{-1}{ }^{34}$. Essas emissões de $\mathrm{NH}_{3}$ estão associadas principalmente às indústrias de fertilizantes e de matérias-primas nitrogenadas para as indústrias de fertilizantes, e também das siderúrgicas ${ }^{32}$. Em 2004, Guimarães e de Mello ${ }^{35}$ estimaram um fluxo de emissão diário das águas da Baía de Guanabara de 3,5 a 3,8 $t \mathrm{~N}$. Assumindo-se uma representatividade anual desses valores, é possível que a emissão anual de $\mathrm{NH}_{3}$ das águas da Baía de Guanabara seja da ordem de $1300 t \mathrm{~N}$, ou seja, quatorze vezes maior que as emissões de $\mathrm{NH}_{3}$ do complexo industrial de Cubatão. Portanto, as emissões de $\mathrm{NH}_{3}$ da Baía de Guanabara, juntamente com as de outras possíveis fontes (porém não inventariadas) na RMRJ, devem contribuir para os elevados fluxos de deposição de $\mathrm{NH}_{4}^{+}$verificados na FODM do PARNASO.

Da mesma forma que o fluxo de deposição úmida de $\mathrm{N}$ inorgânico, os fluxos de exc- $\mathrm{SO}_{4}{ }^{2-}$ nas duas áreas remotas situadas na Bacia Amazônica (Tabela 4) são muito semelhantes, i.e., próximos a 50 mol ha ${ }^{-1}$ ano $^{-1}$. O fluxo de deposição úmida de exc- $\mathrm{SO}_{4}^{2-}$ na FODM do PARNASO foi de $302 \mathrm{~mol} \mathrm{ha}^{-1}$ ano $^{-1}$, i.e., seis vezes maior que os fluxos de exc- $\mathrm{SO}_{4}^{2-}$ verificados na Bacia Amazônica. Em relação às demais áreas remotas citadas na Tabela 4, o fluxo de exc- $\mathrm{SO}_{4}{ }^{2-}$ no PARNASO superou em muito os fluxos de exc- $\mathrm{SO}_{4}{ }^{2-}$ em Torres Del Paine $(60 \text { vezes })^{30}$ e na Ilha de Amsterdam (11 vezes) ${ }^{25}$.

O fluxo de deposição úmida de exc- $\mathrm{SO}_{4}{ }^{2-}$ no PARNASO foi duas vezes maior que o verificado na Floresta Experimental de Hubbard Brook (New Hampshire, EUA) ${ }^{32}$ em 2004. Ainda em 2004, o maior fluxo de deposição úmida de $\mathrm{SO}_{4}{ }^{2-}$ nos EUA ocorreu no sudeste do estado do Ohio (292 mol ha- $\left.\mathrm{ano}^{-1}\right)^{32}$. Em El Verde (Porto Rico), o fluxo de deposição umidade de exc- $\mathrm{SO}_{4}{ }_{4}^{2-}$, medido por McDowell et al. ${ }^{31}$, foi de $145 \mathrm{~mol} \mathrm{ha}^{-1} \mathrm{ano}^{-1}$, que, da mesma forma que o $\mathrm{NO}_{3}^{-}$, teve como origem parcial o transporte de poluentes da América do Norte durante o período de inverno.

O fluxo de deposição úmida de exc- $\mathrm{SO}_{4}{ }^{2-}$ na FODM do PARNASO foi quase três vezes superior ao medido na sede do PNI $\left(115 \mathrm{~mol} \mathrm{ha}^{-1} \mathrm{ano}^{-1}\right)^{21}$. Na bacia do rio Piracicaba (SP), os fluxos de deposição úmida de $\mathrm{SO}_{4}^{2-}$ variaram de $67 \mathrm{~mol} \mathrm{ha}^{-1}$ ano $^{-1}$ (em Santa Maria) a $127 \mathrm{~mol} \mathrm{ha}^{-1} \mathrm{ano}^{-1}$ (em Campinas) ${ }^{36}$. O fluxo de exc-SO ${ }_{4}^{2-}$ no PARNASO, entretanto, é superado pelo valor estimado por Vautz et al..$^{33}$ (1700 mol ha ${ }^{-1}$ ano $\left.^{-1}\right)$ para trechos da Serra do Mar que estão sob a influência das emissões do complexo industrial de Cubatão.

\section{Fluxos de deposição seca}

No PARNASO, os fluxos de deposição seca corresponderam a $1 \%$, no caso do íon $\mathrm{H}^{+}$, e 5-6\%, no caso dos íons $\mathrm{NH}_{4}^{+}, \mathrm{NO}_{3}^{-}$e $\mathrm{SO}_{4}^{2-}$, dos fluxos de deposição total (deposição úmida + deposição seca) (Tabela 5). Na costa sul da Ilha Grande (RJ), utilizando o mesmo tipo de coletor, de Souza et al. ${ }^{15}$ verificaram que os fluxos de deposição
Tabela 5. Fluxos de deposição total (úmida + seca) (em mol ha ${ }^{-1}$ ano $^{-1}$ )* na sede do Parque Nacional da Serra dos Órgãos (PARNASO; Teresópolis, RJ; altitude $=1000 \mathrm{~m}$ ) - valores em parênteses expressam os percentuais da contribuição para a deposição total

\begin{tabular}{lccc}
\hline & Deposição Úmida & Deposição Seca & Deposição Total \\
\hline $\mathrm{H}^{+}$ & $154(99 \%)$ & $1,6(1 \%)$ & 156 \\
$\mathrm{NH}_{4}^{+}$ & $591(94 \%)$ & $40,1(6 \%)$ & 631 \\
$\mathrm{NO}_{3}^{-}$ & $247(95 \%)$ & $13,5(5 \%)$ & 261 \\
$\mathrm{SO}_{4}{ }^{-2}$ & $311(94 \%)$ & $18,3(6 \%)$ & 329 \\
$\mathrm{Exc}^{-} \mathrm{SO}_{4}{ }^{2-}$ & $302(95 \%)$ & $17,0(5 \%)$ & 319 \\
\hline
\end{tabular}

$* 1$ ha $=10^{4} \mathrm{~m}^{2}$.

seca de $\mathrm{H}^{+}, \mathrm{NH}_{4}^{+}, \mathrm{NO}_{3}^{-}$e $\mathrm{SO}_{4}^{2-}$ corresponderam respectivamente a 3 , 10,43 e $50 \%$ da deposição total.

Embora a técnica aplicada seja mais eficiente para coleta de partículas sedimentáveis ${ }^{1,37}$, uma parcela dos íons $\mathrm{NH}_{4}^{+}, \mathrm{NO}_{3}^{-}{\mathrm{e} \mathrm{SO}_{4}^{2-}}^{2-}$ depositados no compartimento destinado à coleta da deposição seca pode ser atribuída à deposição de gases muito solúveis em água, tais como $\mathrm{NH}_{3}, \mathrm{HNO}_{3}$ e $\mathrm{SO}_{2}$, o que pode ocorrer sempre que a superfície interna do recipiente coletor estiver umedecida, por exemplo, durante a ocorrência de nevoeiros ${ }^{38}$.

O fluxo de deposição seca de partículas muito pequenas e gases é difícil de ser estimado face ao grande número de variáveis envolvidas em seu controle. Sehmel ${ }^{1}$ mostra que a deposição seca de partículas e gases é controlada pelas propriedades físicas e químicas das próprias partículas (e.g., diâmetro, densidade, higroscopicidade, solubilidade etc) e gases (e.g., solubilidade, reatividade química etc); variáveis meteorológicas (e.g., estabilidade atmosférica, velocidade do vento, radiação solar, umidade relativa etc) e características diversas relativas aos diferentes tipos de superfícies de deposição (vegetação, solo, rocha e água). Por exemplo, de Mello et al. ${ }^{37}$ observaram que os fluxos de deposição seca de $\mathrm{NO}_{3}^{-}$e exc- $\mathrm{SO}_{4}^{2-}$ foram em média, respectivamente, duas e seis vezes maiores sobre placas de Petri mantidas continuamente com água destilada que sobre diferentes tipos de superfícies artificiais secas.

Portanto, é possível que com base na técnica de coleta adotada no presente trabalho tenha-se subestimado os fluxos de deposição seca de $\mathrm{N}$ inorgânico e $\mathrm{S}$, em virtude de sua maior eficiência para partículas grossas ("coarse particles"), ou seja, aquelas de tamanho superior a 2,5 $\mu \mathrm{m}$, por possuírem maior velocidade de deposição $0^{3,17,39}$.

\section{Fluxos de deposição total}

O fluxo de deposição total (úmida + seca) de $\mathrm{N}$ inorgânico na FODM do PARNASO, medido por meio do coletor automático de deposição úmida e seca, foi de $892 \mathrm{~mol} \mathrm{ha}^{-1}$ ano $^{-1}$, dos quais $70 \%$ foram atribuídos ao $\mathrm{NH}_{4}^{+}$e o restante ao $\mathrm{NO}_{3}^{-}$(Tabela 5). Na Reserva Biológica de Paranapiacaba (SP), local sujeito à influência dos poluentes atmosféricos originários das emissões do complexo industrial de Cubatão e onde a precipitação anual é da ordem de $3380 \mathrm{~mm}$, em meados da década de 80, Domingos et al..$^{40}$ encontraram um fluxo de $\mathrm{N}$ inorgânico de $1790 \mathrm{~mol} \mathrm{ha}^{-1} \mathrm{ano}^{-1}$ por meio de coletores de deposição total ("bulk deposition"), sendo que $85 \%$ foram atribuídos ao $\mathrm{NH}_{4}^{+} \mathrm{e}$ o restante ao $\mathrm{NO}_{3}$.

Do fluxo de deposição total de $\mathrm{N}$ inorgânico medido no PARNASO, somente $6 \%\left(54 \mathrm{~mol} \mathrm{ha}^{-1} \mathrm{ano}^{-1}\right)$ ocorreram sob a forma de deposição seca (Tabela 5). Essa parcela está aquém do que geralmente é relatado pela literatura para fluxos de deposição seca de $\mathrm{N}$ inorgânico ${ }^{4,16-18,41,42}$. Sttodard ${ }^{41}$ estimou a contribuição da deposição seca de $\mathrm{N}$ a partir de valores de fluxo de deposição úmida, 
assumindo que a deposição seca representa, em geral, $35 \%$ da deposição total de N. Segundo Andersen e Hovmand ${ }^{16}$, os fluxos de deposição seca de $\mathrm{NH}_{3}$ em florestas da Holanda e Dinamarca são comparáveis aos fluxos de deposição úmida de $\mathrm{NH}_{4}^{+}$e $\mathrm{NO}_{3}^{-}$juntos. Holland et al. ${ }^{4}$ computaram fluxos médios de deposição total de $\mathrm{N}$ para os Estados Unidos e Europa de 440 e $540 \mathrm{~mol} \mathrm{ha}^{-1} \mathrm{ano}^{-1}$, respectivamente, dos quais, em média, a deposição seca representou $58 \%$ da deposição total nos Estados Unidos e 55\% na Europa. No Brasil, a partir dos fluxos de deposição úmida de $\mathrm{N}$ inorgânico medidos por Lara et al. ${ }^{36}$ em quatro cidades da bacia do rio Piracicaba, cuja média foi de $360 \mathrm{~mol} \mathrm{ha}^{-1} \mathrm{ano}^{-1}$, Krusche et al. ${ }^{43}$ atribuíram um fluxo de deposição total de $\mathrm{N}$ para a bacia do Piracicaba de $640 \mathrm{~mol} \mathrm{ha}^{-1} \mathrm{ano}^{-1}$. Assumindo-se que na área de estudo do presente trabalho o fluxo de deposição seca de $\mathrm{N}$ possa representar de 30 a $50 \%$ do fluxo de deposição total de N, como geralmente relatado pela literatura, estima-se que o aporte atmosférico de $\mathrm{N}$ inorgânico na FODM do PARNASO encontre-se na faixa de 1200 a $1700 \mathrm{~mol} \mathrm{ha}^{-1} \mathrm{ano}^{-1}$.

O fluxo de deposição total (úmida + seca) de exc- $\mathrm{SO}_{4}{ }^{2-}$ medido na FODM do PARNASO foi de $319 \mathrm{~mol} \mathrm{ha}^{-1}$ ano $^{-1}$, dos quais $95 \%$ foram atribuídos à deposição úmida e somente $5 \%$ à deposição seca (Tabela 4). Na Floresta Experimental de Hubbard Brooks (FEHB), em New Hamshire (EUA), o fluxo de deposição total de $\mathrm{SO}_{4}^{2-}$ medido como "bulk deposition" no final da década de 90 foi de $266 \mathrm{~mol} \mathrm{ha}^{-1} \mathrm{ano}^{-1}{ }^{44}$. Para este mesmo período, através do uso de um modelo parametrizado com concentrações de $\mathrm{SO}_{2}$ e $\mathrm{SO}_{4}{ }^{2-}$ (predominantemente como partículas finas), variáveis meteorológicas e características da vegetação local, Likens et al. ${ }^{44}$ estimaram para a FEHB um fluxo de deposição seca de $\mathrm{S}$ (como $\mathrm{SO}_{2}$ e partículas) de $57 \mathrm{~mol} \mathrm{ha}^{-1}$ ano $^{-1}$ (i.e., $21 \%$ da deposição total). Entretanto, eles alertaram para o fato de que outros dois modelos foram aplicados para estimativa do fluxo de deposição seca de $\mathrm{S}$ na FEHB e todos apresentaram resultados discordantes entre si. O mais divergente, baseado no balanço de massa de $\mathrm{S}$ na bacia, apresentou um resultado quatro vezes superior ao valor supracitado.

A interceptação de gotículas de nuvens e nevoeiro, especialmente pelas plantas, é uma outra forma de transferência de nutrientes e poluentes da atmosfera para a superfície. Este processo, também conhecido por deposição oculta ("occult deposition"), é também uma forma de deposição úmida, mas que, na prática, exige o uso de sistemas de coleta especiais ${ }^{45,46}$ ou aplicação de modelos para estimativa da velocidade de deposição de gotículas de nuvens ${ }^{47}$. Face à freqüente ocorrência de nuvens e nevoeiro nas áreas com cobertura de FODM nas vertentes da Serra dos Órgãos voltadas para o Atlântico, estudos dessa forma de deposição necessitam ser realizados.

Vautz et al. ${ }^{33}$ estimaram os fluxos de deposição de $\mathrm{NH}_{4}^{+}, \mathrm{NO}_{3}{ }^{-} \mathrm{e}$ $\mathrm{SO}_{4}^{2-}$, via gotículas de nuvens ("cloud droplets"), na Serra do Mar (altitude ca. 900 m), em local sujeito à influência das emissões do complexo industrial de Cubatão. Estes foram respectivamente 59, 40 e $47 \mathrm{~mol} \mathrm{ha}^{-1}$ ano $^{-1}$ e representaram 6,8 e $3 \%$ dos fluxos de deposição úmida estimados para aqueles íons. Entretanto, sabe-se que em outras áreas de atmosfera poluída dos Estados Unidos e Europa a contribuição da deposição via gotículas de nuvens e nevoeiro é bem mais expressiva em relação à deposição úmida e deposição total ${ }^{18,41,46}$. Em Fichtelgebirge (Alemanha), Thalmann et al..$^{46}$ determinaram que a deposição oculta (atribuída à neblina) contribui com um adicional de $60-85 \%$ do $\mathrm{N}$ e $\mathrm{S}$ em relação ao que é depositado via água de chuva. Em Lägeren (Suíça), Burkard et al. ${ }^{18}$ estimaram um fluxo de deposição total de $\mathrm{N}$ inorgânico de $1870 \mathrm{~mol} \mathrm{ha}^{-1}$ ano $^{-1}(26,2 \mathrm{~kg} \mathrm{~N}$ ha ${ }^{1}$ ano $^{-1}$ ), dos quais $57 \%$ foram atribuídos à deposição seca, $27 \%$ à deposição úmida e $16 \%$ à deposição oculta.

\section{CONCLUSÕES}

$\mathrm{Na}$ área estudada do Parque Nacional da Serra dos Órgãos, o pH da água de chuva variou de 4,5 a 6,9, com MPV de 5,3, correspondendo

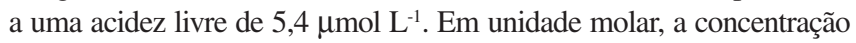
MPV de $\mathrm{NH}_{4}^{+}$foi duas vezes maior que a de $\mathrm{SO}_{4}^{2-}$ e duas vezes e meia maior que a de $\mathrm{NO}_{3}^{-}$. Em média, $97 \%$ do $\mathrm{SO}_{4}^{2-}$ total originaram-se da oxidação do $\mathrm{SO}_{2}$. A razão molar $\left[2\left(\right.\right.$ exc- $\left.\left.^{-S^{2-}}\right)+\mathrm{NO}_{3}^{-}\right] /\left[\mathrm{NH}_{4}^{+}+\mathrm{H}^{+}\right]$foi 1,1 , sugerindo que o controle do $\mathrm{pH}$ é exercido predominantemente pelas seguintes substâncias: $\mathrm{H}_{2} \mathrm{SO}_{4}, \mathrm{HNO}_{3}$ e $\mathrm{NH}_{3}$.

A elevada precipitação na área de estudo $\left(\sim 2800 \mathrm{~mm}^{\mathrm{ano}}{ }^{-1}\right)$ é um fator climático importante que contribui para a transferência de poluentes da atmosfera para a superfície. Os fluxos de deposição úmida de $\mathrm{NH}_{4}^{+}, \mathrm{NO}_{3}^{-}$e exc-SO ${ }_{4}^{2-}$ foram $591 \mathrm{~mol} \mathrm{ha}^{-1} \mathrm{ano}^{-1}(8,3$ $\left.\mathrm{kg} \mathrm{NH}_{4}^{+}-\mathrm{N} \mathrm{ha}^{-1} \mathrm{ano}^{-1}\right), 247 \mathrm{~mol} \mathrm{ha}^{-1} \mathrm{ano}^{-1}\left(3,5 \mathrm{~kg} \mathrm{NO}_{3}^{-}-\mathrm{N} \mathrm{ha}^{-1} \mathrm{ano}^{-1}\right)$ e $302 \mathrm{~mol} \mathrm{ha}^{-1} \mathrm{ano}^{-1}\left(8,3 \mathrm{~kg} \mathrm{SO}_{4}{ }^{2-}-\mathrm{S} \mathrm{ha}^{-1} \mathrm{ano}^{-1}\right)$. Os fluxos de deposição seca de $\mathrm{N}$ inorgânico e $\mathrm{S}$ medidos representaram 5-6\% da deposição total (úmida + seca). Entretanto, com base em estudos realizados em outras regiões do mundo, que estimam que a deposição seca de $\mathrm{N}$ deva corresponder a 30-50\% da deposição total de $\mathrm{N}$ inorgânico, presume-se um aporte anual de $\mathrm{N}$ inorgânico na faixa de 1200-1700 mol ha ${ }^{-1}$ ano $^{-1}\left(17-24 \mathrm{~kg} \mathrm{~N} \mathrm{ha}^{-1}\right.$ ano $^{-1}$ ) para a FODM da Serra dos Órgãos. Se estes valores expressam o efetivo aporte de $\mathrm{N}$ inorgânico nessa área, vale dizer que superam a carga crítica de $\mathrm{N}$ (15 kg N ha ${ }^{-1}$ ano $^{-1}$ ) estabelecida para vários ecossistemas europeus ${ }^{9}$. Portanto, o presente trabalho sugere que a vertente atlântica da Serra dos Órgãos está susceptível a impactos negativos resultantes da deposição de poluentes atmosféricos.

\section{AGRADECIMENTOS}

Ao Conselho Nacional de Desenvolvimento Científico e Tecnológico (CNPq), pelo apoio financeiro concedido ao projeto 474113/2003-5; ao Fundo Nacional do Meio Ambiente (FNMA), pelo apoio financeiro concedido ao projeto "Deposições Atmosféricas" ( $\left.n^{\circ} 1108 / 94\right)$ e à toda administração do Parque Nacional da Serra dos Órgãos, especialmente E. B. V. de Castro e C. C. de Faria pela valorização e apoio dado às atividades de pesquisa científica conduzidas nessa Unidade de Conservação.

\section{REFERÊNCIAS}

1. Sehmel, G. A.; Atmos. Environ. 1980, 14, 983.

2. Pryor, S. C.; Barthelmie, R. J.; Mar. Pollut. Bull. 2000, 41, 220.

3. Wesely, M. L.; Hicks, B. B.; Atmos. Environ. 2000, 14, 2261.

4. Holland, E. A.; Dentener, F. J.; Braswell, B. H.; Sulzman, J. M.; Biogeochemistry 1999, 46, 7

5. Aber, J. D.; Nadelhoffer, K. J.; Steudler, P.; Melillo, J. M.; BioScience 1989, 39, 378.

6. Fisher, D. C.; Oppenheimer, M.; Ambio 1991, 20, 102.

7. Russel, K. M.; Galloway, J. N.; Macko, S. A.; Moody, J. L.; Scudlark, J. R.; Atmos. Environ. 1998, 32, 2453.

8. Oliveira, R. F.; Revista FEEMA 1995, julho-agosto, 46.

9. Phoenix, G. K.; Kevin Hicks, W.; Cinderby, S.; Kuylenstierna, J. C. I.; Stock, W. D.; Dentener, F. J.; Giller, K. E.; Austin, A. T.; Lefroy, R. D. B.; Gimeno, B. S.; Ashmore, M. R.; Ineson, P.; Global Change Biology 2006, 12,470 .

10. FEEMA - Fundação Estadual de Engenharia do Meio Ambiente; Inventário de Fontes Emissoras de Poluentes Atmosféricos da Região Metropolitana do Rio de Janeiro, Departamento de Planejamento Ambiental/Divisão de Qualidade do Ar, Rio de Janeiro, 2004.

11. FIDERJ - Fundação Instituto de Desenvolvimento Econômico e Social do Rio de Janeiro; Indicadores Climatológicos, Governadoria do Estado do Rio de Janeiro/Secretaria de Planejamento e Coordenação Geral, Rio de Janeiro, 1978.

12. Barbiére, E. B.; Kronemberger, D. M. P.; Cadernos de Geociências 1994, $12,57$. 
13. http://www.ibama.gov.br/parnaso/, acessada em Junho 2006.

14. Drummond, J. A.; Devastação e Preservação Ambiental no Rio de Janeiro, Ed. da U. F. F.: Niterói, 1997.

15. de Souza, P. A.; de Mello, W. Z.; Maldonado, J.; Evangelista, H.; Quim. Nova 2006, 29, 471.

16. Andersen, H. V.; Hovmand, M. F.; Forest Ecology and Management 1999, 114,5 .

17. Krupa, S. V.; Environ. Pollut. 2003, 124, 179

18. Burkard, R.; Bützberger, P.; Eugster, W.; Atmos. Environ. 2003, 37, 2979.

19. Galloway, J. N.; Likens, G. E.; Tellus 1978, 30, 71.

20. Ayers, G. P.; Fukuzaki, N.; Gillett, R. W.; Selleck, P. W.; Powell, J. C.; Hara, H.; J. Atmos. Chem. 1998, 30, 301.

21. de Mello, W. Z.; Almeida, M. D.; Environ. Pollut. 2004, 129, 63.

22. Keene, W. C.; Pszenny, A. A. P.; Galloway, J. N.; Hawley, M. E.; J. Geophys. Res. 1986, 91, 6647.

23. Galloway, J. N.; Likens, G. E.; Keene, W. C.; Miller, J. M.; J. Geophys. Res. 1982, 87, 8771 .

24. Williams, M. R.; Fisher, T. R.; Melack, J. M.; Atmos. Environ. 1997, 31, 207.

25. Galloway, J. N.; Gaudry, A.; Atmos. Environ. 1984, 18, 2649.

26. Galloway, J. N.; Charlson, R. J.; Andreae, M. O.; Rodhe, H.; The Biogenic Cycling of Sulfur and Nitrogen in the Remote Atmosphere, D. Reidel Publishing Company: Dordrecht, 1985.

27. Saltzman, E. S.; Cooper, W. J.; Biogenic Sulfur in the Environment, American Chemical Society: Washington, 1989.

28. Andreae, M. O.; Talbot, R. W.; Berresheim, H.; Beecher, K. M.; J. Geophys. Res. 1990, 95, 16987.

29. Andreae, M. O.; Talbot, R. W.; Andreae, T. W.; Harriss, R. C.; J. Geophys. Res. 1988, 93, 1616

30. Galloway, J. N.; Keene, W. C.; Likens, G. E.; J. Geophys. Res. 1996, 101, 6883.

31. McDowell, W. H.; Sánchez, C. G.; Asbury, C. E.; Pérez, C. R. R.; Atmos. Environ. 1990, 24A, 2813
32. http://nadp.sws.uiuc.edu, acessada em Junho 2006

33. Vautz, W.; Pahl, S.; Pilger, H.; Schilling, M.; Klockow, D.; Atmos. Environ. 2003, 37, 3287

34. CETESB - Companhia de Tecnologia de Saneamento Ambiental; Amônia na Atmosfera de Cubatão, Diretoria de Engenharia Ambiental/Departamento de Qualidade Ambiental, São Paulo, 1998.

35. Guimarães, G. P.; de Mello, W. Z.; Quim. Nova 2006, 29, 54

36. Lara, L. B. L. S.; Artaxo, P.; Martinelli, L. A.; Victoria, R. L.; Camargo, P. B.; Krusche, A.; Ayers, G. P.; Ferraz, E. S. B.; Ballester, M. V.; Atmos. Environ. 2001, 35, 4937.

37. de Mello, W. Z.; Souza, M. P.; Motta, J. S. T.; Ciência e Cultura 1987, 39, 1075

38. Cape, J. N.; Leith, I. D.; Atmos. Environ. 2002, 36, 5983.

39. Kulshrestha, U. C.; Granat, L.; Engardt, M.; Rodhe, H.; Atmos. Environ. $\mathbf{2 0 0 5}, 39,7403$

40. Domingos, M.; Poggiani, F.; Struffaldi-de Vuono, Y.; Silveira-Lopes, M. I. M.; Revta Brasil. Bot. 1995, 18, 119.

41. Stoddard, J. L. Em Environmental Chemistry of Lakes and Reservoirs; Baker, L. A., ed.; American Chemical Society: Washington, DC, 1994, cap. 8.

42. Galloway, J. N.; Dentener, F. J.; Capone, D. G.; Boyer, E. W.; Howarth, R. W.; Seitzinger, S. P.; Asner, G. P.; Cleveland, C. C.; Green, P. A.; Holland, E. A.; Karl, D. M.; Michaels, A. F.; Porter, J. H.; Townsend, A. R.; Vörösmarty, C. J.; Biogeochemistry 2004, 70, 153

43. Krusche, A. V.; Camargo, P. B.; Cerri, C. E.; Ballester, M. V.; Lara, L. B L. S.; Victoria, R. L.; Martinelli, L. A.; Environ. Pollut. 2003, 121, 389.

44. Likens, G. E.; Driscoll, C. T.; Buso, D. C.; Mitchell, M. J.; Lovett, G. M.; Bailey, S. W.; Siccama, T. G.; Reiners, W. A.; Alewell, C.; Biogeochemistry 2002, 60, 235.

45. Krupa, S. V.; Environ. Pollut. 2002, 120, 565.

46. Thalmann, E.; Burkard, R.; Wrzesinsky, T.; Eugster, W.; Klemm, O.; Atmos. Res. 2002, 64, 147.

47. Reynolds, B.; Fowler, D.; Smith, R. I.; Hall, J. R.; J. Hydrol. 1997, 194, 305 